\title{
Invasion mechanism in human melanoma cells
}

\author{
Qinghong Kong ${ }^{1} \cdot$ Jianxin Lv ${ }^{1} \cdot$ Guanlin Wang ${ }^{1}$ (I)
}

Received: 15 June 2018 / Accepted: 31 July 2018 / Published online: 3 August 2018

o) Springer Science+Business Media, LLC, part of Springer Nature 2018

To the editor,

We are glad to congratulate Ciolczyk-Wierzbicka for their article [1] in which they observed the possible role of $\mathrm{N}$-cadherin and selected downstream protein kinases: PI3K, ERK1/2, and mTOR in cell invasion in four human malignant melanomas (WM793, Lu1205, WM115, and WM2664). After separate use or combination treatment of siRNA for $\mathrm{N}$-cadherin and downstream protein kinases inhibitors, all tested melanoma cell lines showed reduction in invasion via conventional Boyden transwell methods and activity decline of MMP-2 and MMP-9 by western blot and gelatin zymography compared to control cells. Finally, the mechanism of invasion through $\mathrm{N}$-cadherin/FGFR interaction, PI3K signaling, and MEK-ERK pathway was discussed.

In Ciolczyk-Wierzbicka et al.'s study, they cited suggestion of Hazan et al. [2] which was the 21st reference that $\mathrm{N}$-cadherin functionally interacted with FGF receptor, causing sustained downstream signaling by PI3K, and through MEK-ERK promotes cell survival, migration, and invasion. However, in Hazan's article, PI3K was not mentioned at all. Moreover, U0126 was mistakenly written into U126 in all of figures and someplace of text part. U0126 is a ERK 1/2 kinase inhibitor via blockade MEK1/2 kinase activity [3]. It is likely to cause confusion when read as U126. These issues should be amended in the current study.

Acknowledgements Funding was provided by National Natural Science Foundation of China (Grant No. 81360162).

\section{Compliance with Ethical Standards}

Conflict of interest The authors declare no conflict interest.

Ethical approval There are no human participants and/or animals contained in this paper.

\section{References}

1. Ciolczyk-Wierzbicka D, Laidler P. The inhibition of invasion of human melanoma cells through $\mathrm{N}$-cadherin knock-down. Med Oncol. 2018;35(4):42. https://doi.org/10.1007/s1203 2-018-1104-9.

2. Hazan RB, Qiao R, Keren R, Badano I, Suyama K. Cadherin switch in tumor progression. Ann $\mathrm{N}$ Y Acad Sci. 2004;1014:155-63.

3. Duncia JV, Santella JB III, Higley CA, Pitts WJ, Wityak J, Frietze WE, et al. MEK inhibitors: the chemistry and biological activity of U0126, its analogs, and cyclization products. Bioorg Med Chem Lett. 1998;8(20):2839-44.
Guanlin Wang

glwang83@foxmail.com

1 Faculty of Enviromental Science and Engineering, Kunming University of Science and Technology, 727 South Jing Ming Road, Chenggong County, Kunming 650500, Yunnan, China 